\title{
Structural, Thermal and Electrical Property of Polycrystalline $\mathrm{LaLiMo}_{2} \mathrm{O}_{8}$
}

\author{
Sanjaya Brahma ${ }^{1 *}$, Ram Naresh Prasad Choudhary ${ }^{2}$, Awalendra Kumar Thakur ${ }^{3}$, \\ Srinivasarao Ajjampur Shivashankar ${ }^{1}$ \\ ${ }^{1}$ Materials Research Centre, Indian Institute of Science, Bangalore, India; ${ }^{2}$ Department of Physics, Institute of Technical Education \\ and Research, Siksha O Anusandhan University, Bhubaneswar, India; ${ }^{3}$ Department of Physics and Meteorology, Indian Institute of \\ Technology, Kharagpur, India. \\ Email: *sanjayaphysics@gmail.com
}

Received August 20 $0^{\text {th }}, 2011$; revised October $6^{\text {th }}, 2011$; accepted October $15^{\text {th }}, 2011$

\begin{abstract}
This research article reports electrical characterization of a rare earth molybdate based on combination of rare earth $\left(\mathrm{La}^{3+}\right)$ and alkali $\left(\mathrm{Li}^{+}\right)$metal ions. The experimental observation suggests the negative temperature coefficient of resistance behavior of the material. The material has been prepared by standard solid state reaction method, where the synthesis conditions have been optimized by thermal analysis. A possible mechanism for the formation of the polycrystalline $\mathrm{LaLiMo}_{2} \mathrm{O}_{8}$ is reported. A systematic analysis has been done to determine the crystal structure of the powder material and it was found that the powder material was crystallized to tetragonal unit cell structure. Electrical properties have been studied using a.c. impedance measurement. The temperature variation of electrical conductivity of the material shows typical Arrhenius behavior. The activation energy evaluated from conductivity data works out to be $\sim 0.94 \mathrm{ev}$.
\end{abstract}

Keywords: Powders; Solid State Reaction; X-Ray Methods; Thermal Properties; Electrical Properties

\section{Introduction}

Polytungstates and polymolybdates based either on rare earth metals $(\mathrm{R}=\mathrm{La}, \mathrm{Nd}, \mathrm{Dy}, \mathrm{Sm}, \mathrm{Gd}$ etc. [1-8] or alkali metals ( $\mathrm{Li}, \mathrm{Na}, \mathrm{K}$, etc.) [8-13] have drawn substantial attention in recent years because of their physical properties such as successive phase transition, ferroelectric/ ferroelastic behavior [1,2], phosphors [3], and ionic conduction etc. [7]. The structural diversity results in existence of the polymorphism in rare earth molybdates arising as a result of flexibility in their coordination number and geometry of both rare-earth cation ( $\mathrm{La}^{3+}$ for example) [14] and molybdate ion $\left(\mathrm{Mo}^{6+}\right.$ for example) [15] centers. This property permits possibility of $6-12$ as well as $4-7$ coordinates with various coordination polyhedra for both trivalent rare earth cation and hexavalent molybdate cation respectively [9]. As a consequence, replacement/ substitution of rare earth cation with other species in polymolybdates becomes practically feasible although it is accompanied by drastic changes in structure and properties.

Although molybdates based on rare earths are not new, discovery of ionic conduction in molybdates (especially $\mathrm{La}_{2} \mathrm{Mo}_{2} \mathrm{O}_{9}$ or similar other modifications) is a recent

${ }^{*}$ Corresponding author. phenomena [7]. Conventionally ceramic oxides exhibiting ionic conduction has been described in literature belonging only to four different structural classes 1) Fluorite type [16] (YSZ); 2) Perovskites [17] (doped $\mathrm{LaGaO}_{3}$ ); 3) Inter growth Perovskites $/ \mathrm{Bi}_{2} \mathrm{O}_{3}$ layered type [18] (BIMEVOX); 4) Pyrochlores [19] $\left(\mathrm{Gd}_{2} \mathrm{Ti}_{2} \mathrm{O}_{7}\right)$. Recently, Lacorre and coworkers [7] have shown that ionic conduction is a practical reality in ceramic oxides whose crystal structure does not belong to any of the above structural classes (typically $\mathrm{La}_{2} \mathrm{Mo}_{2} \mathrm{O}_{9}$ ). This has provided a new impetus to study oxomolybdates at intermediate and higher temperatures.

Anionic conductors (more specifically oxygen ion conductors) have drawn considerable attention recently because of their suitability for applications in solid oxide fuel cells (SOFC), oxygen sensors, oxygen pumping devices, etc. [20,21]. In addition to above, the presence of vacant d-cells in molybdates also provides coloration efficiency by charge transport within the molybdate group. This inherent property of the molybdates makes it suitable for open circuit memory and electrochromic applications specially when doped with alkali metals such as ( $\mathrm{Li}, \mathrm{Na}, \mathrm{K}$ etc. [22]).

Literature survey indicates that studies on rare earth and alkali metal modified molybdates of different struc- 
tural forms have not attracted much attention. In this paper, we report the structural, thermal, and electrical properties of such a molybdate based on a combination of both rare earth and alkali metal i.e., $\mathrm{LaLiMo}_{2} \mathrm{O}_{8}$. Previously reported literatures reveal that two different structural forms of $\mathrm{LaLiMo}_{2} \mathrm{O}_{8}$ (tetragonal and orthorhombic) could be possible [23-25]. However, a detail of the synthesis procedure is not available in any open journal literature. Kessler et al., [26] reported two different phases of a $\mathrm{LiLaMo}_{2} \mathrm{O}_{8}$ synthesized by sol-gel synthesis, one is fine powder of $\alpha-\mathrm{LiLaMo}_{2} \mathrm{O}_{8}$ which forms at $600^{\circ} \mathrm{C}$ and the other is $\beta-\mathrm{LiLaMo}_{2} \mathrm{O}_{8}$ that forms at $800^{\circ} \mathrm{C}$. The XRD pattern has been recorded in a very narrow Bragg angle range $\left(2 \theta=20^{\circ}-40^{\circ}\right)$ and the pattern has not been indexed and also it has not explained details about the actual crystal structure. Here, we report the optimized synthesis conditions based on simple solid state reaction and details of structural analysis. The material sample $\mathrm{LaLiMo}_{2} \mathrm{O}_{8}$ was prepared using a simple, standard solid state reaction technique based on the optimized calcination temperature. Electrical properties of the material sample have also been studied by impedance analysis.

\section{Experimental Procedure}

\subsection{Sample Preparation}

Polycrystalline samples of $\mathrm{LaLiMo}_{2} \mathrm{O}_{8}$ were prepared by a standard solid state reaction method using optimized conditions of calcination temperature, by thermal analysis technique. Appropriate stoichiometric ratio of high purity (AR grade) precursors $\left(\mathrm{Li}_{2} \mathrm{Co}_{3}, \mathrm{MoO}_{3}\right.$, and $\left.\mathrm{La}_{2} \mathrm{O}_{3}\right)$ were taken initially and mixed mechanically for $2 \sim 3 \mathrm{~h}$. This is followed by further mechanical grinding in methanol to achieve homogenous mixing of the constituents. The calcination temperature was found to be $550^{\circ} \mathrm{C}$. The powder so obtained after calcination was cold pressed into cylindrical pellets of (diameter $10 \mathrm{~mm}$ and thickness $1.3 \mathrm{~mm}$ ) with polyvinyl alcohol (PVA) as the binder. An isostatic pressure of $\sim 3 \times 106 \mathrm{Nm}^{-2}$ were applied for pelletization. The sample pellets so obtained were then sintered at $600^{\circ} \mathrm{C}$ for $12 \mathrm{~h}$. The sintered pellet was then polished to make their faces smooth and parallel followed by coating with a conductive silver paint. The coated sample pellets were dried at $150^{\circ} \mathrm{C}$ for $2-3 \mathrm{~h}$ before carrying out any measurement.

\subsection{Sample Characterization}

Thermal analysis (TGA/DTA/DTG) was carried out to check the possibility of formation of the desired phase. 5 $\mathrm{mg}$ of the physical mixture of the material sample was taken in an alumina crucible using a PERKIN ELMER of simultaneous thermal analysis system (STA) (air flow at
$100 \mathrm{ml} / \mathrm{min})$. The experiment was carried out over the temperature range $\left(50^{\circ} \mathrm{C}\right.$ to $\left.800^{\circ} \mathrm{C}\right)$ at a constant heating rate of $10^{\circ} \mathrm{C}$ per minute using alumina as the reference material. X-ray diffraction (XRD) studies were carried out to confirm the phase formation. XRD pattern was recorded in the Bragg angle range $5^{\circ}<2 \theta<90^{\circ}$ at room temperature with a diffractometer (PHILIPS, model: PW1710) using $\mathrm{CuK} \alpha$ radiation (1.5418 $\AA$ ) as the source. The microstructural details were studied using scanning electron microscopy (SEM) analysis. It was carried out using a high resolution scanning electron microscope (SEM: JOEL JSM model 6700F). The sample pellet was gold coated with a thin film of gold prior to being scanned under high resolution field emission gun. Electrical measurements were carried out using a computer controlled impedance analysis (HIOKI LCR HI tester, Model: 3532) as a function of temperature over a range of frequencies (100 Hz to $1 \mathrm{MHz}$ ).

\section{Results and Discussion}

Thermal analysis techniques (TGA/DTA/DTG) provide very important and vital information including its synthesis conditions, nature of reaction at a particular temperature, phase transition etc. Figure 1 shows a TGA curve of the as prepared physical mixture.

The pattern shows a gradual mass loss of the material sample on heating from $50^{\circ} \mathrm{C}$ onwards. Two small kinks with change in slope were noticed at the points $\mathrm{A}$ and $\mathrm{B}$ corresponding to temperatures $\sim 150^{\circ} \mathrm{C}$ and $330^{\circ} \mathrm{C}$ respectively. These may be attributed to dehydration of water present in the material and intermediate reaction stages respectively. Subsequent heating is accompanied by a progressive mass loss with a drastic steep loss beginning at $510^{\circ} \mathrm{C}$ onwards that attains a saturation value at $\sim 550^{\circ} \mathrm{C}$. Beyond $550^{\circ} \mathrm{C}$ there is no appreciable loss in mass with rise in temperature indicating stability of the

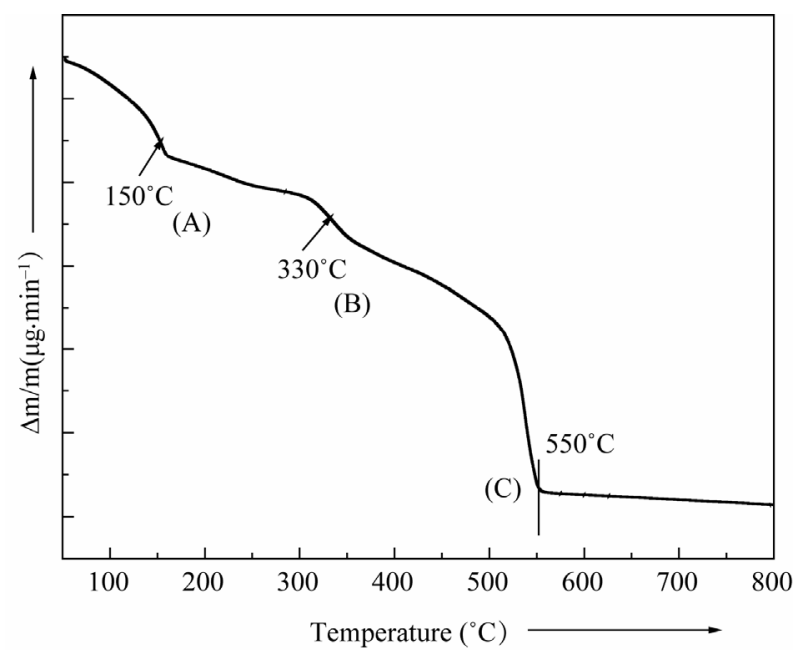

Figure 1. Thermal gravimetry pattern (TGA) of $\mathrm{LaLiMo}_{2} \mathrm{O}_{8}$. 
residual material and completion of reaction leading to the formation of final product. The total mass loss up to $550^{\circ} \mathrm{C}$ has been estimated to be $10.5 \%$. The maximum mass loss occurring in the temperature range $510^{\circ} \mathrm{C}$ and $550^{\circ} \mathrm{C}$ may be attributed to the evolution of $\mathrm{CO}_{2}$ gas. These observations were found to be in good agreement with the differential thermal analysis (DTA) pattern of Figure 2(a) and differential thermogravimetry (DTG) pattern of Figure 2(b). Three maxima occurring at the points G, H and I in the DTG thermogram may be attributed to the mass loss due to dehydration, intermediate reaction steps and $\mathrm{CO}_{2}$ evolution towards the end of the reaction. The removal of the water content present in the material and $\mathrm{CO}_{2}$ at the completion of the reaction appears to be endothermic process as indicated by two endotherms (points D \& F) in DTA pattern. The presence of small exothermic peaks in the DTA pattern (point E) beyond $250^{\circ} \mathrm{C}$ may be attributed to the beginning of reaction among mixed precursors corresponding to the intermediate steps.

A systematic XRD study was carried out to observe the various stages of changes in the course of reaction at different calcination temperature and to confirm final phase formation of the material. Figure 3(a) shows the XRD spectra of the as prepared physical mixture calcined at different temperatures. The intensity of the individual spectrum was normalized to observe the change in the intensity of the individual XRD peaks. Preliminary observation shows that the single phase of $\mathrm{LaLiMo}_{2} \mathrm{O}_{8}$ was obtained at $600^{\circ} \mathrm{C}$. XRD pattern were recorded for the powder sample calcined at $625^{\circ} \mathrm{C}$ and $650^{\circ} \mathrm{C}$ and it was found that the phase remains stable at $650^{\circ} \mathrm{C}$. Initial observations lead to conclude that the material is polycrystalline in nature. The XRD pattern recorded at $600^{\circ} \mathrm{C}$ was refined by JANA 2000 (a standard crystallographic program to solve, refine the XRD pattern). All the diffraction peaks were indexed and it matches well with the standard JCPDS data [23]. Detailed structural analysis indicates that the material under investigation crystallizes to tetragonal unit cell system. Table 1 shows the crystallographic parameters of the standard JCPDS data and the refined data.

It is observed that the tetragonal phase of $\mathrm{LaLiMo}_{2} \mathrm{O}_{8}$ ceramics started to form at $550^{\circ} \mathrm{C}$ as shown in Figure 3(b). However, a careful observation shows the presence of impurities from the starting precursor materials. Further increase in calcination temperature leads to the formation of single phase of tetragonal $\mathrm{LaLiMo}_{2} \mathrm{O}_{8}$ at $600^{\circ} \mathrm{C}$. XRD spectrum was recorded upto $650^{\circ} \mathrm{C}$ to check the thermal stability of the tetragonal phase of $\mathrm{LaLiMo}_{2} \mathrm{O}_{8}$ and it was found that the material was found to be stable at this temperature.

Based on XRD and thermal analysis results, it was postulated that the following reaction might be a possi-

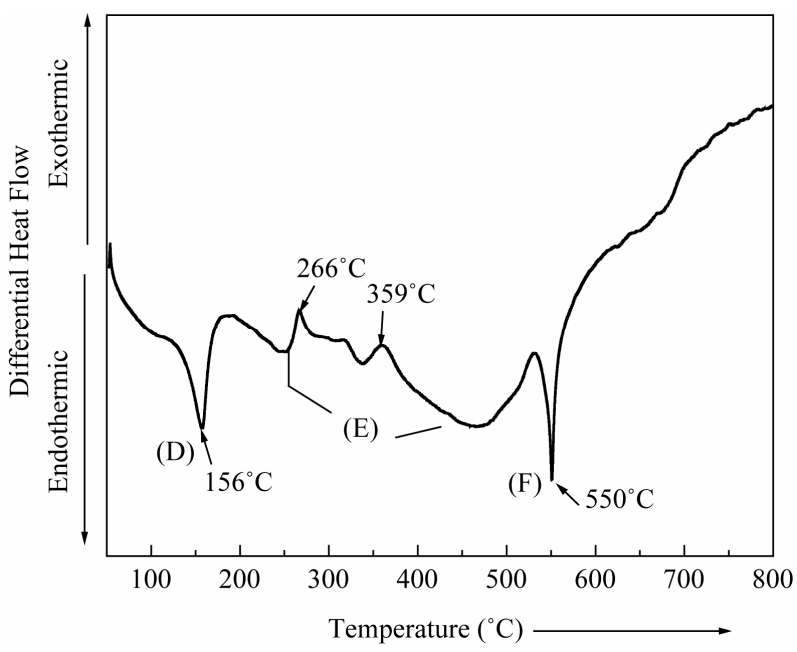

(a)

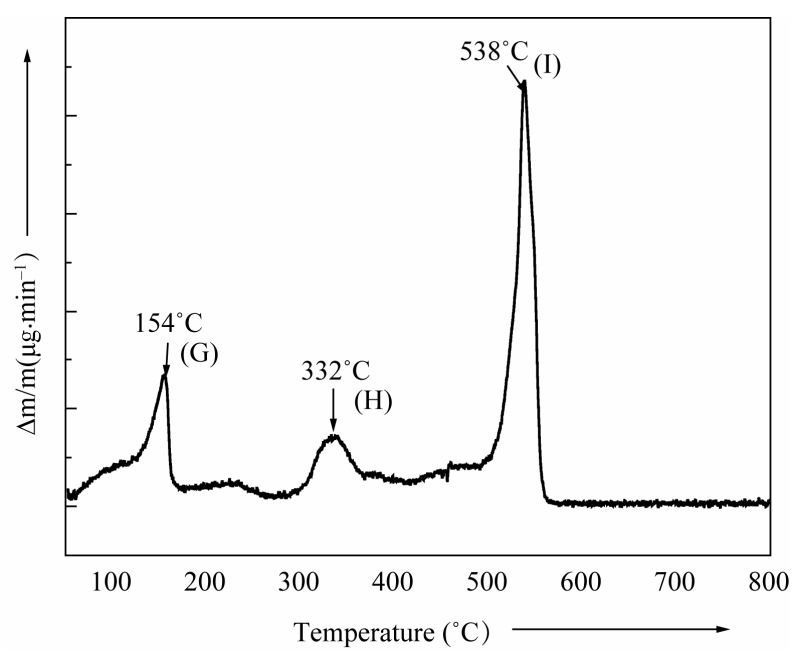

(b)

Figure 2. (a) Differential thermal analysis pattern (DTA) of $\mathrm{LaLiMo}_{2} \mathrm{O}_{8}$; (b) Differential thermal gravimetry (DTG) pattern of $\mathrm{LaLiMo}_{2} \mathrm{O}_{8}$.

Table 1. Structural parameters of $\mathrm{LaLiMo}_{2} \mathrm{O}_{8}$.

\begin{tabular}{ccc}
\hline & $\begin{array}{c}\text { PDF No: } \\
00-018-0734\end{array}$ & $\begin{array}{c}\text { Experimental Result } \\
\text { after Refinement }\end{array}$ \\
\hline Crystal System: & Tetragonal & Tetragonal \\
Space Group: & I41/a & I41/a \\
$\mathrm{a}(\AA):$ & 5.30 & 5.308721 \\
$\mathrm{~b}(\AA):$ & 5.30 & 5.308721 \\
$\mathrm{c}(\AA):$ & 11.61 & 11.708508 \\
$\alpha\left(^{\circ}\right):$ & 90.00 & 90.0000 \\
$\beta\left(^{\circ}\right):$ & 90.00 & 90.0000 \\
$\gamma\left({ }^{\circ}\right):$ & 90.00 & 90.0000 \\
Volume of Cell $\left(10^{\wedge} 6 \mathrm{pm}^{\wedge} 3\right):$ & 326.12 & 329.97 \\
\hline
\end{tabular}




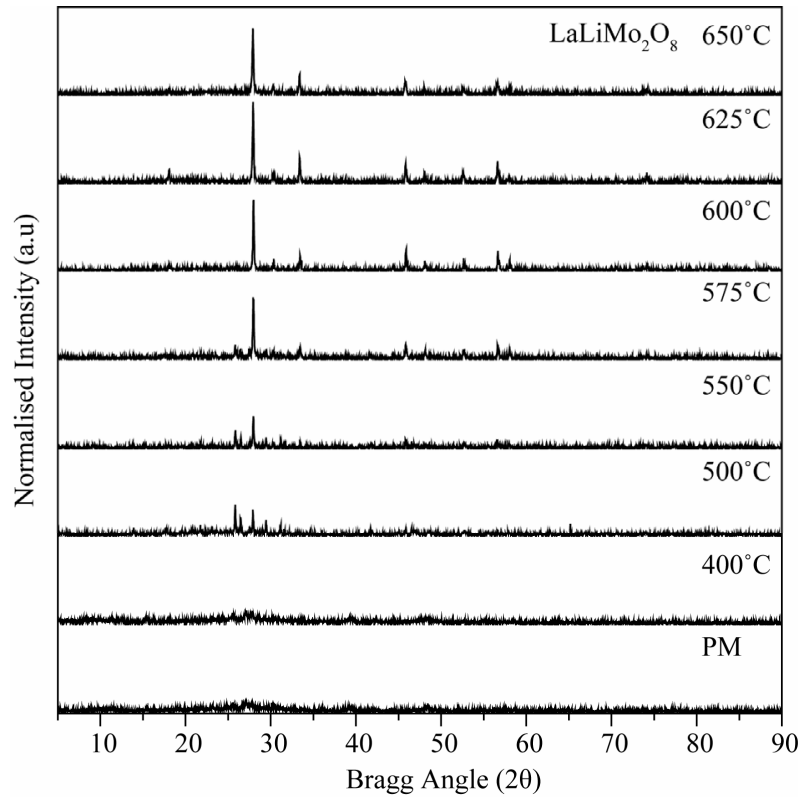

(a)

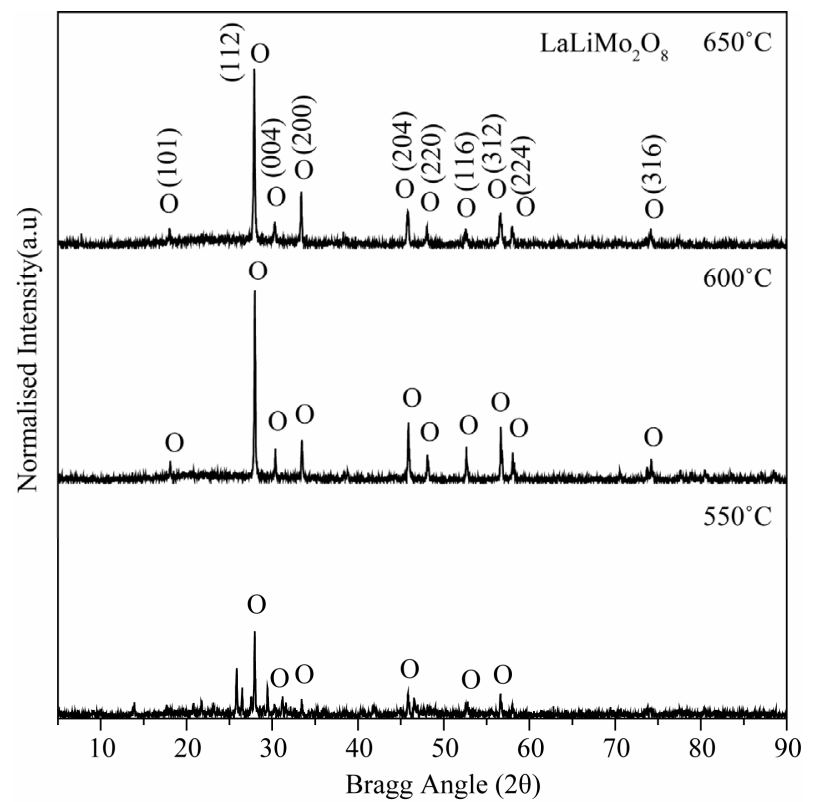

(b)

Figure 3. X-ray diffraction pattern of $\mathrm{LaLiMo}_{2} \mathrm{O}_{8}$. (a) XRD pattern of $\mathrm{LaLiMo}_{2} \mathrm{O}_{8}$ powder calcined at different temperatures; (b) XRD pattern of $\mathrm{LaLiMo}_{2} \mathrm{O}_{8}$ calcined at $550^{\circ} \mathrm{C}$, $600^{\circ} \mathrm{C}$, and $650^{\circ} \mathrm{C}$.

bility when the precursors were heated in the air atmosphere while solid state reaction was taking place.

$$
\begin{aligned}
& \mathrm{La}_{2} \mathrm{O}_{3}+\mathrm{Li}_{2} \mathrm{CO}_{3}+\mathrm{MoO}_{3} \frac{600^{\circ} \mathrm{C}}{\Delta, \text { air }} \\
& \rightarrow 2 \mathrm{LaLiMo}_{2} \mathrm{O}_{8}+\mathrm{CO}_{2} \uparrow
\end{aligned}
$$

The surface property and microstructure of the material sample in the present studies were investigated using
SEM. The SEM picture of the sample pellet is shown in the Figure 4. The micrograph reveals a polycrystalline nature of material and confirms porous microstructure as indicated by the presence of voids of uneven distribution. Further, the micrograph indicates that the polycrystalline grains have typical dimension in the range of $1-3 \mu \mathrm{m}$.

The electrical behavior of the system was studied over a wide range of frequency and temperature using a.c. technique of complex impedance spectroscopy. Figure 5 shows complex impedance spectrum (Nyquist Plot) of $\mathrm{LaLiMo}_{2} \mathrm{O}_{8}$ measured at different temperatures. The impedance spectrum is characterized by the presence of semicircular arcs whose nature of evolution appears to be changing with rise in temperatures [Figure 5]. Each semicircular arc in the impedance pattern can be attributed to a parallel combination of resistance and capacitance and its intercept with the real axis (X-axis) gives an estimate of bulk material conductivity. As temperature rises the arcs progressively become semicircular with shift in the center of their arc towards origin of the complex plane plot [Figure 5]. Further, a general feature of the impedance pattern is the decrease in the bulk resistance of the sample with rise in temperature i.e., negative

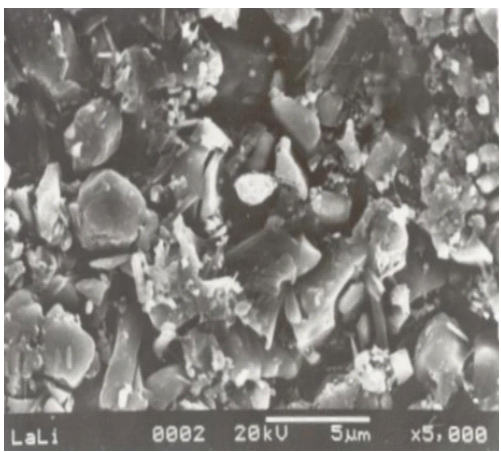

Figure 4. Scanning electron micrograph (SEM) of LaLi$\mathrm{Mo}_{2} \mathrm{O}_{8}$ at room temperature.

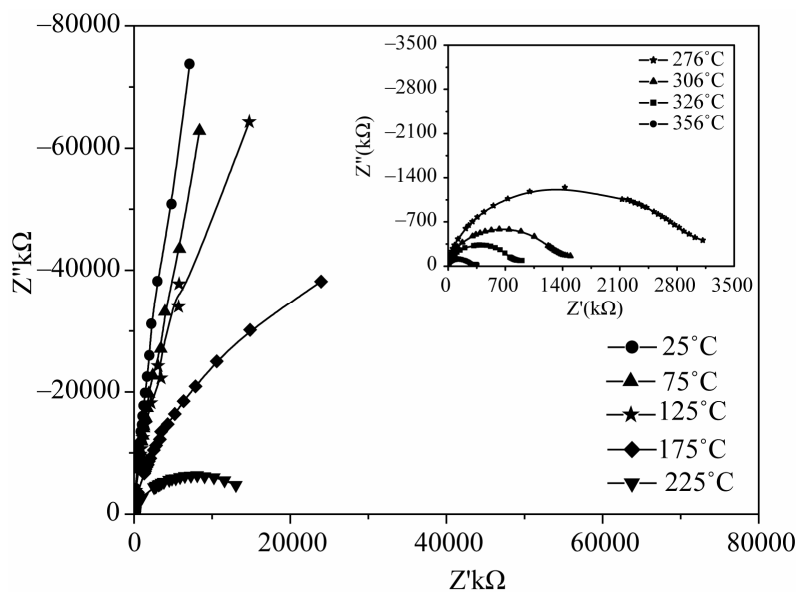

Figure 5. Complex impedance spectrum (Nyquist Plot) of $\mathrm{LaLiMo}_{2} \mathrm{O}_{8}$. 
temperature coefficient of resistance (NTCR) behavior in the material, a well-established property in semiconducting materials.

The impedance data was used to estimate the bulk resistance $\left(R_{b}\right)$ at different temperatures and hence to calculate d.c. conductivity $\left(\sigma_{d c}\right)$ of the sample as a function of temperature using the formula, $\sigma_{\text {d.c. }}=\frac{1}{R_{b}} * \frac{l}{A}$, where $R_{b}=$ bulk resistance $l=$ sample thickness, $A=$ Sample area. The typical variation of $d$.c. conductivity of La$\mathrm{LiMo}_{2} \mathrm{O}_{8}$ as a function of temperature is shown in the Figure 6. The conductivity variation indicates an increase of conductivity with increase in temperature which is a typical Arrhenius type behavior having linear dependence of conductivity on temperature. This type of temperature dependence of d.c. conductivity indicates that the electrical conduction in the material is a thermally activated process. It can be explained in accordance with the relation $\sigma_{d c}=\sigma_{0} \exp \left[\frac{E_{a}}{k T}\right]$, where $\sigma_{0}=$ pre exponential factor, $E_{a}=$ Activation energy, $k=$ Boltzmann constant. In addition to the above, a slight departure from the linear dependence of conductivity has been noticed at lower temperatures. It can be attributed to Mott's type hopping phenomena [27]. A maximum conductivity value of $3.6 \times 10^{-6} \mathrm{~S} \cdot \mathrm{cm}^{-1}$ has been observed at $\sim 400^{\circ} \mathrm{C}$. This is a very high conductivity when compared with room tem- perature value $\left(3.4 \times 10^{-10}\right)$ indicating a jump of nearly four orders of magnitude. This may possibly be related to grain boundary conduction and lowering of the barrier to the mobility of charge carrier with rise in temperature. However, a detailed investigation is required to obtain further evidence for the same.

\section{Conclusion}

A ceramic oxide based on the combination of a rare earth

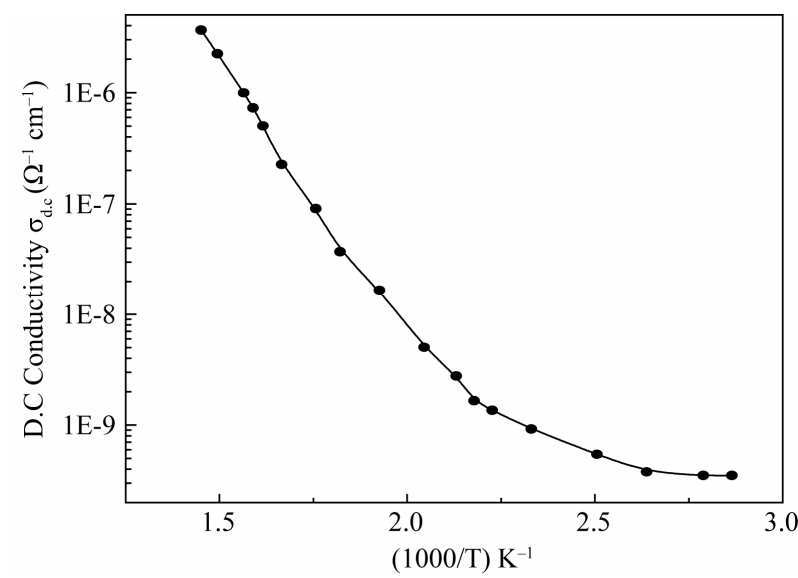

Figure 6. Variation of d.c. conductivity as a function of temperature. and an alkali metal ion, $\mathrm{LaLiMo}_{2} \mathrm{O}_{8}$, was prepared. The preparation conditions have been optimized by carrying out thermal analysis studies. Thermo gravimmetry studies showed maximum mass loss $(\Delta \mathrm{m} / \mathrm{m})$ at a temperature of $550^{\circ} \mathrm{C}$ beyond which it remained constant upto a fairly high temperature limit of $800^{\circ} \mathrm{C}$ providing an evidence for thermal stability of the material. XRD studies confirmed material formation with polycrystalline texture and tetragonal unit cell structure. SEM analysis further confirmed polycrystalline nature of the material. Thermal analysis and XRD study results have enabled us to predict the possible reaction taking place leading to the formation of the material. Our results on electrical properties indicate a typical negative temperature coefficient of resistance (NTCR) behavior.

\section{Acknowledgements}

Sanjaya Brahma acknowledges Council of Scientific and Industrial Research (CSIR) for the award of research associateship and IIT-Kharagpur for initial experimental works.

\section{REFERENCES}

[1] H. J. Borchardt and P. E. Bierstedt, " $\mathrm{Gd}_{2}\left(\mathrm{MoO}_{4}\right)_{3}$ : A Ferroelectric Laser Host," Applied Physics Letters, Vol. 8, No. 2, 1966, pp. 50-52. doi:10.1063/1.1754477

[2] J. Huang, J. Loriers and P. Porcher, "Spectroscopic Properties of $\mathrm{Ln}_{2} \mathrm{MoO}_{6}: \mathrm{Eu}^{3+}$," Journal of Solid State Chemistry, Vol. 43, No. 1, 1982, pp. 87-96. doi:10.1016/0022-4596(82)90218-3

[3] G. Blasse and A. Bril, "On the $\mathrm{Eu}^{3+}$ Flurescence in Mixed Metal Oxides III. Energy Transfer in $\mathrm{Eu}^{3+}$-Activated Tungstates and Molybdates of the Type $\mathrm{Ln}_{2} \mathrm{WO}_{6}$ and $\mathrm{Ln}_{2} \mathrm{MoO}_{6}$," Journal of Chemical Physics, Vol. 45, No. 7, 1966, pp. 2350-2355. doi:10.1063/1.1727945

[4] F. Dubois, F. Goutenoire, Y. Laligant, E. Suard and P. Lacorre, "Ab-Initio Determination of $\mathrm{La}_{2} \mathrm{Mo}_{4} \mathrm{O}_{15}$ Crystal Structure from X-Rays and Neutron Powder Diffraction," Journal of Solid State Chemistry, Vol. 159, No. 1, 2001, pp. 228-233. doi:10.1006/jssc. 2001.9190

[5] R. Subasri, D. Matusch, H. Näfe and F. Aldinger, "Synthesis and Characterization of $\left(\mathrm{La}_{1-x} \mathrm{M}_{x}\right)_{2} \mathrm{Mo}_{2} \mathrm{O}_{9-\delta} ; \mathrm{M}=$ $\mathrm{Ca}^{2+}, \mathrm{Sr}^{2+}$ or $\mathrm{Ba}^{2+}$, Journal of the European Ceramic Society, Vol. 24, No. 1, 2004, pp. 129-137. doi:10.1016/S0955-2219(03)00123-7

[6] H. Naruke and T. Yamase, "Structural Investigation of $\mathrm{R}_{2} \mathrm{Mo}_{4} \mathrm{O}_{15}(\mathrm{R}=\mathrm{La}, \mathrm{Nd}, \mathrm{Sm})$, and Polymorphs of the $\mathrm{R}_{2} \mathrm{Mo}_{4} \mathrm{O}_{15}(\mathrm{R}=$ Rare Earth) Family," Journal of Solid State Chemistry, Vol. 173, No. 2, 2003, pp. 407-417. doi:10.1016/S0022-4596(03)00131-2

[7] P. Lacorre, F. Goutenoire, O. Bohnke, R. Retoux and Y. Laligant, "Designing Fast Oxide-Ion Conductors Based on $\mathrm{La}_{2} \mathrm{Mo}_{2} \mathrm{O}_{9}$," Nature, Vol. 404, No. 6780, 2000, pp. 856-858. doi:10.1038/35009069

[8] V. S. Grunin and I. B. Patrina, "Impurities and Charge 
Compensation in Some Molybdenium Oxides," Physica Status Solidi B, Vol. 123, No. 1, 1984, pp. 353-363. doi: $10.1002 /$ pssb.2221230138

[9] R. D. Shannon, "Revised Effective Ionic Radii and Systematic Studies of Interatomic Distances in Halides and Chalcogenides," Acta Crystallographica Section A, Vol. 32, Part 5, 1976, pp. 751-767. doi:10.1107/S0567739476001551

[10] T. Gnanasekaran, K. H. Mahendran, K. V. G. Kutty and C. K. Mathews, "Phase Diagram Studies on the Na-Mo-O System," Journal of Nuclear Materials, Vol. 165, No. 3, 1989, pp. 210-216. doi:10.1016/0022-3115(89)90197-9

[11] T. Mathews, D. Krishnamurty and T. Gnanasekaran, "An Electrochemical Investigation of the Thermodynamic Properties of $\mathrm{Na}_{2} \mathrm{Mo}_{2} \mathrm{O}_{7}$ and $\mathrm{Na}_{2} \mathrm{NiO}_{2}$," Journal of $\mathrm{Nu}$ clear Materials, Vol. 247, 1997, pp. 280-284. doi:10.1016/S0022-3115(97)00075-5

[12] S. N. Choudhary and R. N. P. Choudhary, "Phase Transitions in $\mathrm{NaLiWO}_{4}$ Ceramics," Materials Letters, Vol. 34, No. 3-6, 1998, pp. 411-414. doi:10.1016/S0167-577X(97)00203-6

[13] S. Takenaka, T. Tanaka, T. Funabiki and S. Yoshida, "Structures of Molybdenum Species in Silica-Supported Molybdenum Oxide and Alkali-Ion-Modified Silica-Supported Molybdenum Oxide," Journal of Physical Chemistry B, Vol. 102, No. 16, 1998, pp. 2960-2969. doi:10.1021/jp980134n

[14] T. Nagasaki, S. Inui and T. Matsui, "Phase Relation in $\mathrm{Li}_{2} \mathrm{MoO}_{4}-\mathrm{Li}_{2} \mathrm{WO}_{4}$ System," Thermochimica Acta, Vol. 352353,2000 , pp. 81-85. doi:10.1016/S0040-6031(99)00441-4

[15] S. Chatterjee, P. K. Mahapatra, R. N. P. Choudhary and A. K. Thakur, "Complex Impedance Studies of Sodium Pyrotungstate- $\mathrm{Na}_{2} \mathrm{~W}_{2} \mathrm{O}_{7}$," Physica Status Solidi A, Vol. 201, No. 3, 2004, pp. 588-595. doi:10.1002/pssa.200306741

[16] H. A. Harwig and A. G. Gerards, "Electrical Properties of the $\alpha, \beta, \gamma$, and $\delta$ Phases of Bismuth Sesquioxide," Journal of Solid State Chemistry, Vol. 26, No. 3, 1978, pp. 265-274. doi:10.1016/0022-4596(78)90161-5
[17] T. Ishihara, H. Matsuda and Y. Takita, "Doped $\mathrm{LaGaO}_{3}$ Perovskite Type Oxide as a New Oxide Ionic Conductor," Journal of the American Chemical Society, Vol. 116, No. 9, 1994, pp. 3801-3803. doi:10.1021/ja00088a016

[18] F. Abraham, M. F. Debreuille-Gresse, G. Mairesse and G. Nowogrocki, "Phase Transitions and Ionic Conductivity in $\mathrm{Bi}_{4} \mathrm{~V}_{2} \mathrm{O}_{11}$ an Oxide with a Layered Structure," Solid State Ionics, Vol. 28-30, Part 1, 1988, pp. 529-532. doi:10.1016/S0167-2738(88)80096-1

[19] S. A. Kramer and H. L. Tuller, "A Novel Titanate-Based Oxygen Ion Conductor: $\mathrm{Gd}_{2} \mathrm{Ti}_{2} \mathrm{O}_{7}$," Solid State Ionics, Vol. 82 , No. 1-2, 1995, pp. 15-23. doi:10.1016/0167-2738(95)00156-Z

[20] B. C. H. Steele, “Oxygen Ion Conductors,” In: T. Takahashi, Ed., Recent Trends and Applications, World Scientific Publishing Co., Singapore, 1989, p. 402.

[21] J. C. Boivin and G. Mairesse, "Recent Material Developments in Fast Oxide Ion Conductors," Chemistry of Materials, Vol. 10, No. 10, 1998, pp. 2870-2888. doi:10.1021/cm980236q

[22] Y. Zhang, S. Kuai, Z. Wang and X. Hu, "Preparation and Electrochromic Properties of Li-Doped $\mathrm{MoO}_{3}$ Films Fabricated by the Peroxo Sol-Gel Process," Applied Surface Science, Vol. 165, No. 1, 2000, pp. 56-59. doi:10.1016/S0169-4332(00)00369-X

[23] JCPDS No-00-018-0734. B. Greenberg, Polytechnic Institute of Brooklyn, Brooklyn, New York, USA, 1965.

[24] JCPDS No-00-026-0850. Klevtsov, et al., Vol. 18, No. 523, 1974.

[25] JCPDS No-01-070-1728. R. F. Klevtsova, Vol. 20, No. $746,1975$.

[26] V. G. Kessler, A. N. Panov, N. Y. Turova and A. Y. Borissevitch, "Solution Stoichiometry Control for Pure Li$\mathrm{LaMo}_{2} \mathrm{O}_{8}$ Phases in Sol-Gel Preparation," Journal of SolGel Science and Technology, Vol. 8, No. 1-3, 1997, pp. 1049-1051. doi:10.1023/A:1018386308334

[27] N. F. Mott, "Metal Insulator Transition," Taylor and Francis, London, 1990. 